\title{
Ecological Regeneration of Obsolete Tourist Resorts
}

\author{
Victor Sánchez Pescador \\ Department of Tourist Environment, University of Las Palmas, Las Palmas 35011, Spain
}

\begin{abstract}
Tourist cities have particular and different use compared with ordinary city. The main users spend most of their time to leisure, and to the enjoyment of the urban environment, so people must be attentive to the changing needs of visitors and be willing to transform their environment based on them. These changes must be environmentally sustainable and based on concepts of economic, environmental and social sustainability, people need to be prepared for the continuous recycling of the existence, and are always seeking to increase the energy efficiency. The rehabilitation in edificatory and urban terms must go hand in hand in this task if people want to achieve the objectives of environmental sustainability, combining the lives of residents with visitors, especially in poor energetic resource areas where the external dependency is very high, that is the case of the Canary Islands, where the scarcity of energy and water make necessary in a very small and densely populated area, the efficient use of resources and thus the reuse and transformation of what exists. The rehabilitation process of the poor quality buildings built in the 1970s has started, so people must not miss this new opportunity to improve environment to make it more sustainable.
\end{abstract}

Key words: Sustainability, water resources, reuse, regeneration, energy, tourism, urban transport.

\section{Introduction}

UNWTO (United Nation World Tourist Organization) expects a continuum growth of the tourism sector worldwide at a ratio of $5 \%$ a year, becoming the global economic sector with the greatest potential of development after the expansion of emerging countries in South America and Asia, with enormous internal markets in development. This scenario of growth in a sector with a high consumption of natural resources highlights the need to adopt short-term measures that minimize the impact on the consumption of energy and water, the main consolidated mass tourism urban centers have to develop their regeneration plans on the basis of sustainable development [1] taking advantage of the pre-existing structures and implementing new measures of savings with the use of renewable energy.

An economic growth of $5 \%$ a year for a planet with increasingly depleted energy exploitation resources is one of the things that people can not afford, and they should not forget that precisely linked to leisure

Corresponding author: Victor Sánchez Pescador, architect, research fields: urban sustainability and transport systems. E-mail: Info@sanchezpescadorarquitectos.com. activities are major consumers of resources. Many of these mass tourist centers, to make the situation worse, are located on islands with limited territories and totally dependent on external contributions, therefore, unsustainable social and environmentally and in many cases are subjected to over exploitation.

With this background, it is essential to treat the entertainment industry through comprehensive planning of the resources existing in destination.

\section{Urban Energy Balance in Tourist Areas}

Canarias is an outermost region of the European Union. It is constituted by seven islands: El Hierro, La Gomera, La Palma, Tenerife, Fuerteventura, Gran Canaria and Lanzarote. The archipelago is located in the northwest coast of the African continent, between the coordinates $27^{\circ} 37^{\prime}$ and $29^{\circ} 25^{\prime}$ of north latitude and $13^{\circ} 20^{\prime}$ and $18^{\circ} 10^{\prime}$ of west longitude. The distance to Africa is only $95 \mathrm{~km}$, in the nearest point.

These Volcanic islands are parts of the natural region of Macaronesia. The climate is subtropical, but it is modified by the height and the northern side. Canarias has four national parks and five Unesco Biosphere Reserves (ESP-8, ESP-12, ESP-16, ESP-30, 
ESP-38). The islands are visited every year for more than 12 million tourists.

The population of the islands is 2,126,769 inhabitants for an area of $7,447 \mathrm{~km}^{2}$, giving a population density of 286 persons per $\mathrm{km}^{2}$, which is one of the highest densities of the EU.

Gran Canaria is one of the major islands which has 845,676 inhabitants with an increasing demographic tend for only $1,560 \mathrm{~km}^{2}$ (Fig. 1). The visiting tourists are $3,305,883$ per year, which is approximately 280,000 tourists per month.

The island has a 99\% external energy dependency which is based on $100 \%$ fossil fuels. The energy demand is $1,710,050$ ton, which is equivalent to 3,782 GW/h. This energy involves transport and urban consumption. The global use of energy per person a day is $3,360 \mathrm{~kW} / \mathrm{h}$ which is equivalent to $2,500,000$ ton of $\mathrm{CO}_{2}$ emissions.

The 3,305,883 tourists per year who visit Gran Canaria consume $8,260,000$ GW which is a tremendous waste of energy for an island whose energetic dependence is $100 \%$ external and based on the fossil fuel combustion. In the same manner, the water resources are scarce, however, the average water consumption of a visitor is more double than the average consumption of a resident, the water demand for tourist leisure activities (pools, golf courses, green areas, water parks etc.) is extremely high and represents an annual consumption of $150 \mathrm{hm}^{3} /$ year, and all this water comes in a 55\% from aquifer resources, which is dramatically reducing the water reservoir.

This reveals the need for action on energy savings to maintain the ecological and environmental balance and make the tourism development sustainable.

\section{Changing the Urban Transport, and Recovery of Transportation Areas}

In the energetic fossil boom of 1960s, energy seemed to be cheap and unlimited which had led to an unregulated development of industrial societies in the last decades, the urban transport accounts $23 \%$ of the energy used, and the growth is $5.3 \%$ per year, which makes the current model unsustainable. It becomes necessary to optimize the public urban transport to make it more efficient by the limitation of the internal urban traffic in tourist areas, and the introduction of new eco-efficient means of mobility (Fig. 2).

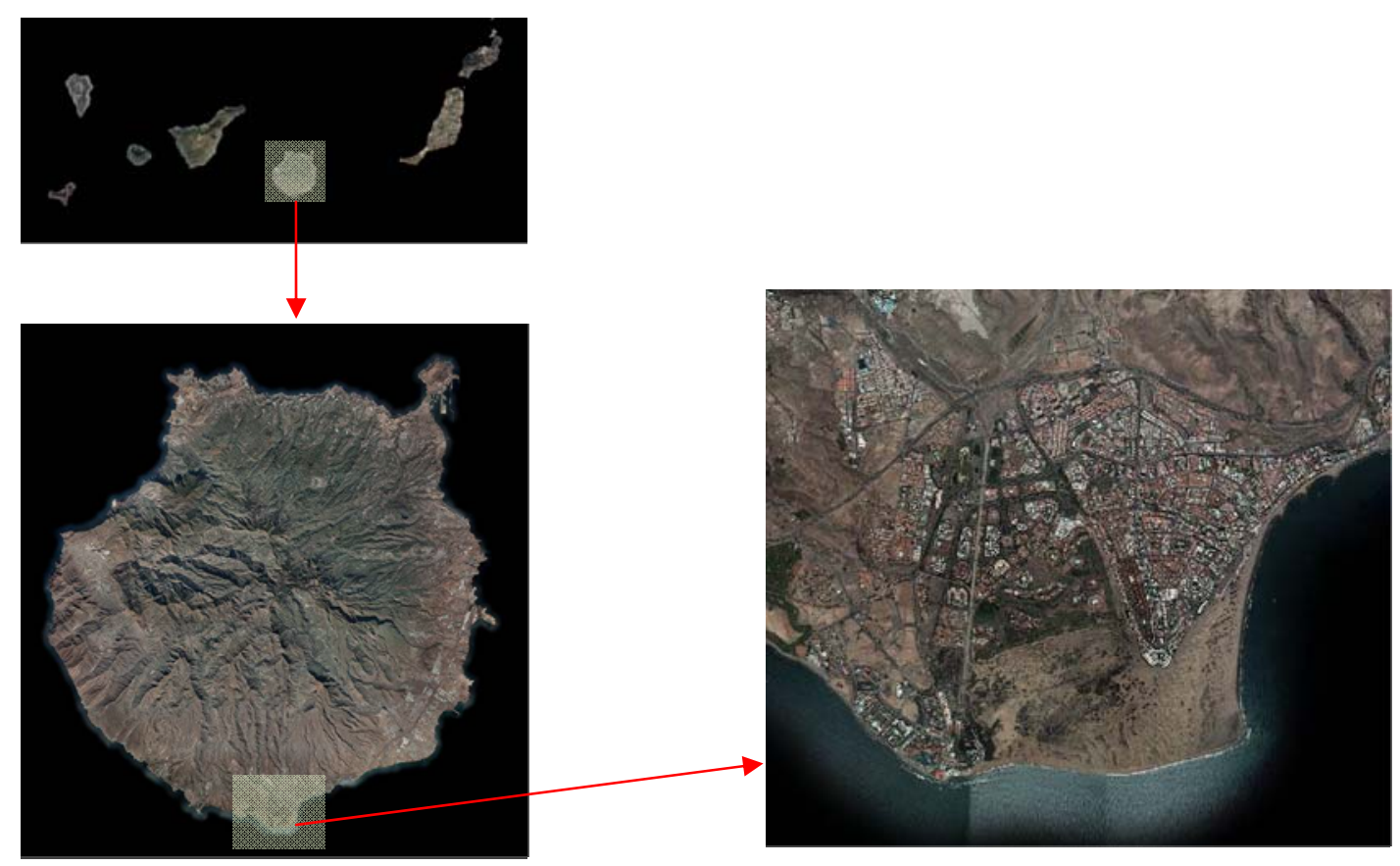

Fig. 1 Canary Islands-Gran Canaria-Playa del Inglés. 

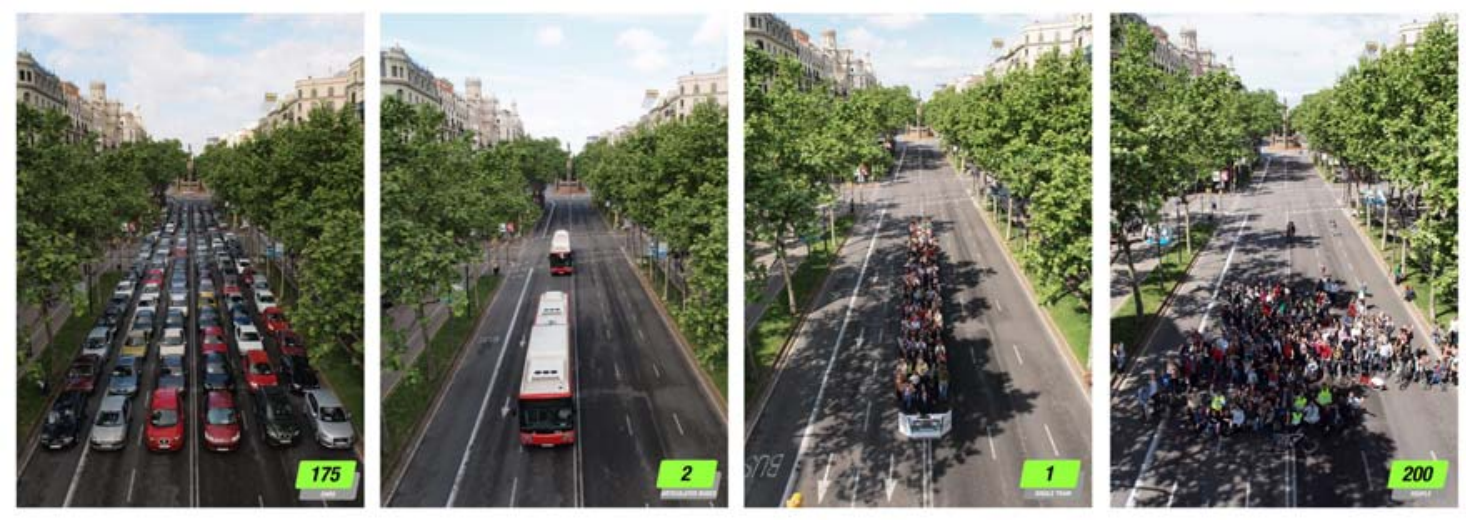

Fig. 2 Public transport against private transport.

One of the best examples of this achievement is owed in Curitiva (Brasil), with the Integrated Transport Network, a system of 2,160 buses that are circulating in the principal axes with dedicated lanes, the operation is the same as a subway transport in surface, with a system of fast lines BRT (Bus Rapit Transit), at a reasonable speed and frequency (Fig. 3). Access is very fast by elevated platforms adapted to the disabled and single payment to enter. This RIT (Rede Integrada de Transporte) transport system has rapidly become the main transport system of the city, responsible for the $85 \%$ of the total urban displacement.

People also must support the transformation of urban spaces into disuse, redefining them for the city and giving them new interpretations. One good example of these is the Highway Cheonggyecheon Seúl. The transformation of urban transport systems carries the resized of urban transport spaces, allowing the colonization of part in these areas to be included as new green lines and public enjoyment spaces used for leisure time, this demands which is even more value in tourist urban areas where leisure time is longer.

The high costs is involved in the transformation of the current global cities to make them cleaner, more sustainable and more efficient, which needs to undergo a rapid transformation to pass through the reinventing of the obsolete urban areas for the new uses requested.
The new cutting edge urban planning moves in the direction of recycling obsolete spaces, the reinterpretation of the areas intended for sustainable urban transport and improving the relationship residence/work, these concepts must be thought about, which are continuity, sustainability, environment and sustainable mobility. In the energy rating certificates of US Green Building Council, LEED (leadership in energy and environmental design) plays an important role in the transport systems and urban mobility in terms of energy certification [2].

\section{Energy Efficiency Improvement of Urban Areas}

The life cycle analysis in the industrial production is fundamental for the evaluation of the final costs of the improvements to undertake, people must not forget the pillars of "sustainability"-the environmental factor, social factor and economic factor, and to keep the balance under the difficult confluence of the three, [3]. This balance is easier to accomplish in urban tourist areas where the environmental factor is fundamental, the social factor is linked to leisure, entertainment and economic factor today, which increasingly depends on the previous two.

Sustainability sought (which is just common sense) is defined in the Brundtland report as "the ability to meet the needs of the present generation without compromising the ability of future generations to meet 
their own needs" [4]. It is necessary to reduce urban energy consumption starting with the implementation of technological improvements of existing urban furnishings. The use of photovoltaic lighting systems

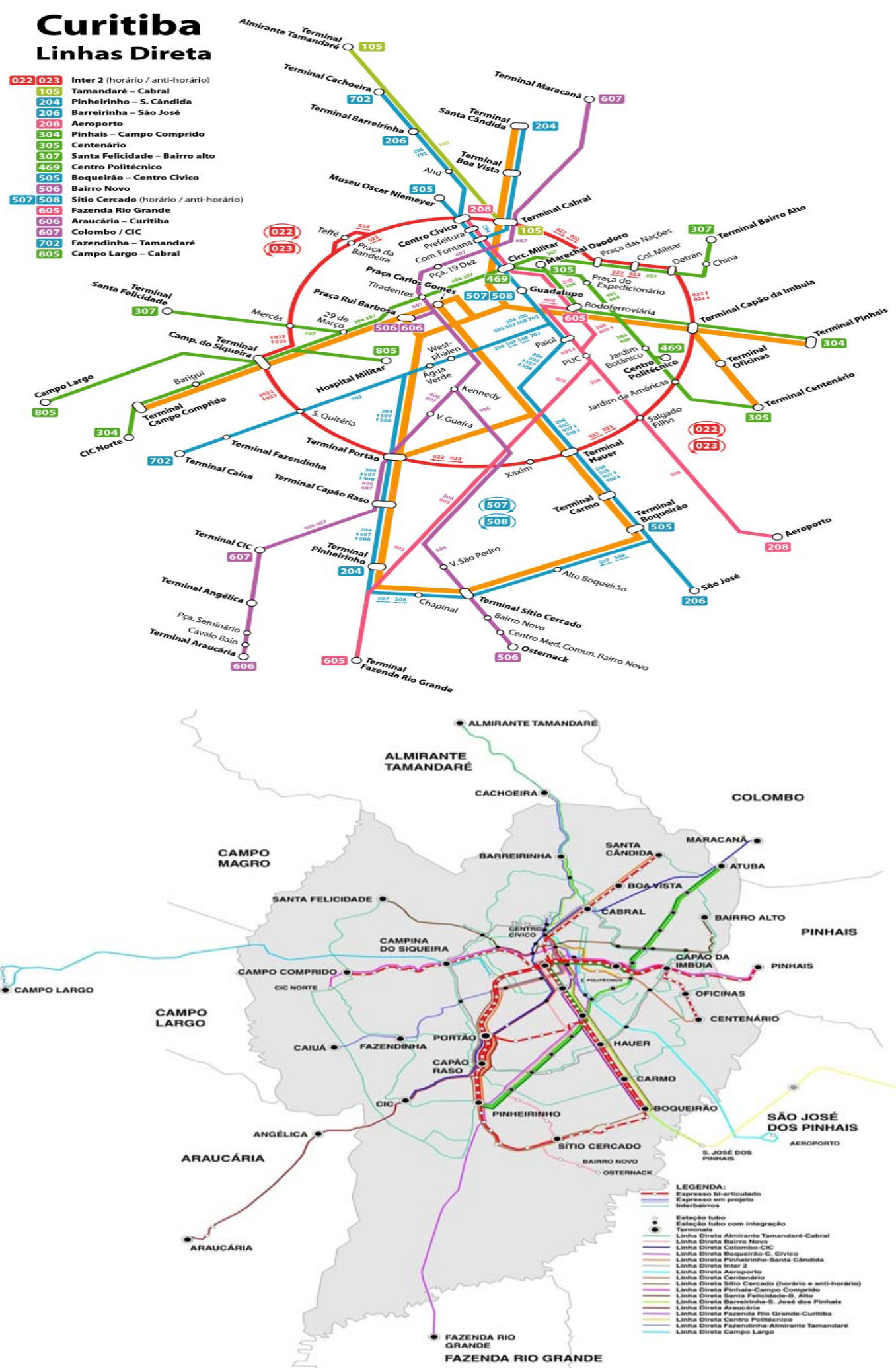

Fig. 3 Curitiba in Brasil, integrated bus transport network. 
combined with LED (light emitting diode) reduces consumption virtually to zero. The use of wind resources in much of the island is highly sustainable, and more with the new urban generators that works well in open coast areas with highly efficient wind that improves the yields [5].

In the Canary Islands, the average annual temperature in the tourist resorts is $26{ }^{\circ} \mathrm{C}$, and the incidence of the sun radiation is $5,738 \mathrm{Wh} / \mathrm{m}^{2} /$ day. This high solar incidence increases the heat island phenomenon that contributes to the warming of urban areas and therefore the energy consumption linked to cooling of buildings, so people must use the highest reflective surfaces in buildings and take advantage of the use of low thermal mass floors to prevent overheating.

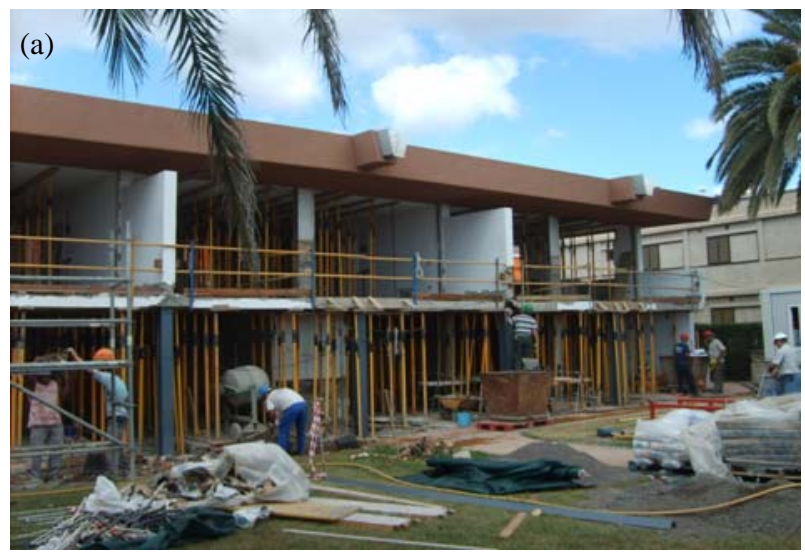

\section{Regeneration of Obsolete Resorts}

Seventy percent of existing tourist buildings in the Canary Islands was built in the 1970s with the phenomenon of mass tourism boom, therefore, people have an obsolete and very inefficient buildings from the energy point of view. Buildings are responsible for $40 \%$ of final energy used, therefore, they urge to act on them reducing their energy needs and improving the contribution of renewable energy systems [6].

\section{Conclusions}

Bearing in mind that buildings consume $40 \%$ of energy resources becomes necessary, an exhaustive study of the focus of life cycle thinking that encompasses the entire construction process from the

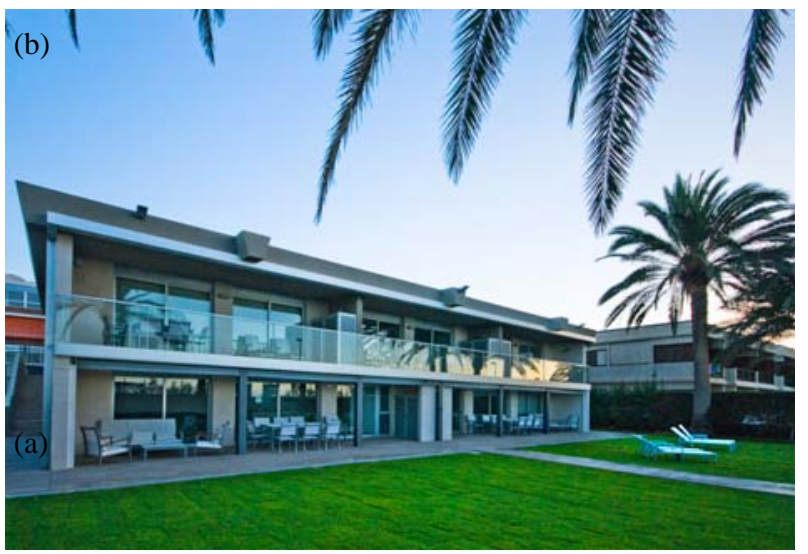

Fig. 4 Rehabilitation of "Las Barcas” apartments: (a) before building; (b) after building.
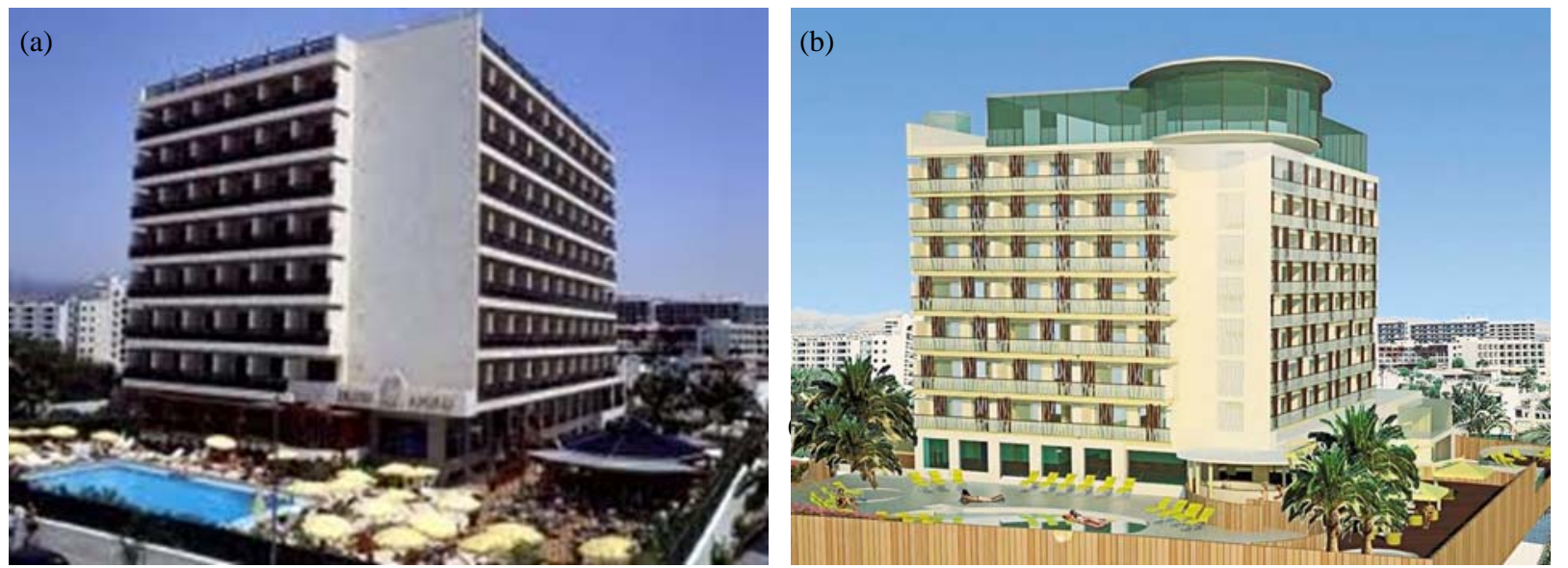

Fig. 5 Rehabilitation of the Apolo Hotel: (a) before building; (b) after building. 
collection of raw materials, the construction, operation and maintenance, reusing and recycling of buildings, thus possible to quantify the energy consumption, carbon footprint and greenhouse gasses throughout the life cycle [7]. The myth of the "Gaia hypothesis" which understands the land as homeostatic system today reveals insufficient, the rehabilitation of built heritage is sustainable and is $60 \%$ energy savings compared to new construction, structure only accounts for $45 \%$ energy savings. Energy savings in the process of rehabilitation is in the vicinity of $0.038 \mathrm{ton} / \mathrm{m}^{2}$ [8] (Figs. 4 and 5) which means thousands of tons of carbon dioxide equivalent not emitted into the atmosphere and an important economic saving, both interventions, building and town planning must be inseparably united in this new process.

In the new urban relationships, the answers must be pursued to these questions:

(1) How to build a sustainable city and in network, starting from retrieved spaces?

(2) How to make a linear park supports with the multi-track structuring character of the city?

(3) How to reconcile the ride with connectivity?

(4) How to introduce public transport alternative to private vehicles?

(5) How to integrate the greenway with pedestrian areas, cross access, adjacent gardens etc. along its route to organize a network of green spaces at a larger scale?

(6) How can the linear park became, environmentally sustainable and improve the city?

(7) How can people experiment with the place?
(8) Is it necessary to increase the green zones?

(9) Are the shaded areas enough?

(10) Are the paved areas sufficient?

"There is no more noble behavior that the attempt to achieve a collective dream. When a city is accepted as a duty their quality of life, when it respects the people who live in it, when it respects the environment, as it prepares for future generations, people share the responsibility for this duty and this shared cause is the only way to achieve that collective dream”, come from Jaime Lerner, mayor of Curitiba.

\section{References}

[1] S. Rueda, Models and Indicators for Sustainable Cities, Fundació Forum Ambiental, European Environment Agency, 1999, http://www.forumambiental. org/pdf/huella.pdf (accessed Jan. 1, 2013).

[2] Green Building and LEED Core Concepts Guide, USGBC (United States Green Building Council), 2009.

[3] General Guide for Life Cycle Assessment—Detailed Guidance, European Commission Printing Office, EU, 2010.

[4] Our Common Future: World Commission on Environment and Development, Brundtland report, UN, 1987.

[5] J.M.F. Salgado, Energy Efficiency in Buildings, AMV (Antonio Madrid Vicente Editions), Spain, 2011.

[6] General Secretary, Analysis of Energy Consumption in the Residential Sector in Spain, Spanish Government Printing Office, Spain, 2011.

[7] R.W. Kates, T.M. Parris, A.A. Leyserowitz, What is sustainable development? Goals, indicators, values and practice, Environment: Science and Policy for Sustainable Development 47 (3) (2005) 8-21.

[8] J.A.T. Rios, R.V. Burke, Building Sustainability, Institute of Construction Sciences, E. Torroja (Ed.), undación Agustín de Betancourt, Madrid, 2012. 